Фиг. 2. Lepidospongia sp. ind. Экз. СГУ, № 122/3429: реконструкция облика скелета: сохранившаяся часть скелета выполнена темно-серым, почка и кратеры - более темным оттенком. Отсутствующая часть скелета показана пунктиром и светло-серым фоном.

Фиг. 3. Paracraticularia sp. ind. Экз. СГУ, № 122/3643 (х 1): фрагмент верхней части дихотомирующих ветвей скелета: $3 a-$ с широкой стороны ветви, на фрагментированное основание почковидного образования; $3 \sigma-\mathrm{c}$ узкой стороны.

Местонахождение Саратов, Лысая гора, нижний сантон.

Фиг. 4. Paracraticularia sp. ind. Экз. СГУ, № 122/3429: реконструкция облика скелета, сохранившаяся часть выполнена темно-серым, основание фрагментированной почки - более темным оттенком. Отсутствующая часть скелета показана пунктиром и светло-серым фоном.

Условные обозначения: О - оскулюм, сс - кратер отделившейся почки; $\mathrm{pc}$ - тело почки.

Фототаблица VII

Фиг. 1. Ventriculites ocreaceus Perv., 1998. Экз. СГУ, № 121/2657 (x 1): $1 a$ - сбоку, на почкообразное образование; 16,1 в - сбоку, с противоположных сторон бокала.
Местонахождение с. Пудовкино, Саратовская область, нижний сантон.

Условные обозначения: О - оскулюм, $\mathrm{VK}$ - верхний край; 1 - линия пережима; $\mathrm{pc}_{1}-\mathrm{pc}_{2}-$ предполагаемые тела почек.

Фототаблица VIII

Фиг. 1. Eurete sp. Экз. СГУ, № 122/4949 (х 0,6): $1 a, 16$ - сбоку, с противоположных широких сторон; 1в- сбоку, с узкой стороны бокала, на почкообразный вырост; 12 сверху; $1 \partial$ - почкообразный вырост $(\mathrm{x} 1,8)$.

Местонахождение «Озерки-03», Саратовская область, нижний сантон.

Условные обозначения: О - оскулюм; $\mathrm{pc}$ - тело почки.

\section{Фототаблица IX}

Фиг. 1. Contubernium ochevi Perv., 1998. Экз. СГУ, № 28 (х 0,75): скелет полной сохранности: $1 a$ - сверху; 16 - снизу; 1 - сбоку; 12 - вид по диагонали сверху; $1 \partial$ - половина верхней части скелета с оскулюмом в центре, субмодули расположены в два ряда по периферии (х 1,5).

Местонахождение Саратов, нижний сантон.

Условные обозначения: О - оскулюм, $\mathrm{VK}$ - верхний край, fsk - основание скелета, subm - субмодуль.

УДК $551.578 .4+502.7$

\title{
РЕЗУЛЬТАТЫ ГЕОХИМИЧЕСКОЙ СНЕГОВОЙ СЬЕМКИ ЛОКАЛЬНОГО УЧАСТКА ТЕРРИТОРИИ САРАТОВА
}

\section{М.В. Решетников, Л.В. Гребенюк ${ }^{1}$, т.Д. Смирнова ${ }^{2}$}

Саратовский государственный университет, лаборатория геоэкологии кафедры геоэкологии E-mail: rmv85@list.ru,

1кафедра охраны окружающей среды и безопасности жизнедеятельности

${ }^{2}$ кафедра аналитической химии

E-mail: smirnovatd@mail.ru

Представлены результаты исследований химического состава снегового покрова локального участка Саратова. Установлено, что по определяемым компонентам состав талой воды соответствует требованиям, предъявляемым к водам рыбных хозяйств, за исключением содержания азота аммония. Сделаны выводы 0 перспективности проведения снегомерных съемок в рамках локальных участков. Подобные работы играют важную роль в образовательном процессе студентов, обучающихся по специальностям экологических направленностей.

Ключевые слова: снеговой покров, химическое загрязнение, локальный участок.

Results of the geochemical snow Survey for a local Area of the Territory of the Saratov City

\section{M.V. Reshetnikov, L.V. Grebenuk, T.D. Smirnova}

Results of the chemical snow survey for a local area of the territory of the Saratov city are presented. It is fixed that composition of water from melted snow is corresponding to water qualitative for fish farming, except of content of nitrogen ammonium. Conclusions on per-

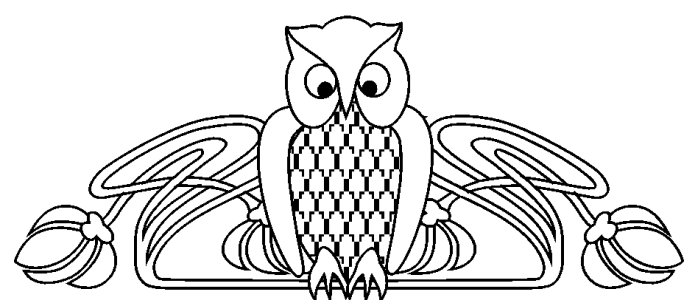

spectives of snow survey of local areas are proposed. Similar works has an important role in educational process of students, studying ecological disciplines.

Key words: snow blanket, chemical pollution, local area.

\section{Введение}

Снеговой покров является исключительно благоприятным объектом при изучении загрязнения природной среды, так как обладает высокой сорбционной способностью. Химический состав снегового покрова формируется под влиянием ряда факторов: поступления различных химических примесей вместе с выпадающими атмосферными осадками, поглощения снегом газов из воздуха и оседания из атмосферы твердых частиц, взаимодействия снегового покрова с земной поверхностью (почвенно-растительным покровом). Несомненно, существенное влияние на химический состав снега оказывает деятельность человека. Геохимическая информация сохраняется в снеговом покрове в течение всего периода снегостояния [1].

Долгое время снег изучался только как один из видов атмосферных осадков. Как показал И.М. Осокин [2], химический состав снега как атмосферных осадков и толщи снежного покрова отличается разнообразием ингредиентов и их количественным содержанием. Первые геохимические исследования снегового покрова на территории 
Российской Федерации были начаты около 60 лет назад [3]. В последнее десятилетие геохимическое изучение снежного покрова все больше привлекает внимание ученых и успешно используется для индикации техногенного загрязнения.

Первые геохимические исследования снегового покрова на территории Саратова проводились в рамках комплексной программы «Экологический мониторинг г. Саратова» (ЭМоС) в 1992 г. и 1994 г. в лаборатории урбоэкологии СГУ под руководством В.З. Макарова, в 1997 г. и 1999 г. работа была продолжена сотрудниками лаборатории геоэкологии СГУ под руководством Э.А. Молостовского. Отбор проб в эти годы проводился практически на всей территории города, со средней плотностью одна проба на один квадратный километр, при общем объеме порядка 500 проб. Этими работами на территории Саратова было выявлено очаговое загрязнение снегового покрова тяжелыми металлами, сульфатами, хлоридами, нитратами и рядом других полютантов. Наметились конфигурация и структура техногенного геохимического поля города и особенности пространственного распространения основных загрязнителей в его пределах.

В настоящее время встал вопрос о характере дальнейших снегомерных исследований, и в частности целесообразности массового опробования всей городской территории с большими объемами дорогостоящих аналитических работ. Возникло вполне обоснованное сомнение в том, что информативность массовых данных вряд ли соответствует затратам на их получение, поскольку в значительной части проб снегомерных съемок 1992-1999 гг. концентрации загрязнителей мало отличались от их фоновых значений и не превышали ПДК [4]. Необходимость уменьшения объемов работ и их удешевления стала вполне очевидной.

В 2005 г. профессором Э.А. Молостовским было предложено проводить на базе лаборатории геоэкологии СГУ регулярные снегомерные съемки на локальных участках городской территории в рамках практических занятий студентовгеоэкологов. В зимний период 2005/06 учебного года была проведена первая межвузовская студенческая снегомерная съемка, в работе которой принимали участие студенты химического и геологического факультетов СГУ и студенты СГТУ. Опираясь на результаты съемок предыдущих лет, на территории города были выделены 6 локальных полигонов, на которых было отобрано 88 проб. В талой воде определялись содержание нитратов, нитритов, гидрокарбонатов, $\mathrm{pH}$, жесткость. Для каждого полигона построен ряд карт распределения определяемых компонентов. Результаты данной работы были озвучены в докладах студентов на 7-й Всероссийской научной конференции студентов, аспирантов и молодых специалистов «Геологи 21 века» и опубликованы в сборнике материалов [5].
Следующая снеговая съемка была осуществлена в зимний период 2007-2008 гг., исследования по ряду причин проводились только на одном полигоне. В талых водах определяется более широкий ряд загрязнителей: азот аммония, нитраты, хлориды, сульфаты, общий фосфор, сухой остаток и рН. В зимний период 2008-2009 гг. было проведено повторное обследование снегового покрова на территории этого же полигона. Результаты геохимических снеговых съемок последних лет локального участка Саратова представлены в данной работе.

\section{Характер загрязнения воздушного бассейна Саратова}

Саратов как крупный промышленный город оказывает существенное воздействие на приземный слой атмосферы. Основными источниками загрязнения атмосферы являются химическое производство, производство нефтепродуктов, электроэнергии и газа, а также автотранспорт.

Объем выбросов загрязняющих веществ в атмосферу от стационарных источников промышленных предприятий и автотранспорта в 2008 г. составил 144,040 тыс. т (в 2007 г. - 140,896 тыс. т). При этом выбросы от стационарных источников промышленных предприятий составили 20,994 тыс. т. Таким образом, вклад автотранспорта в суммарный выброс по Саратову составил $85,4 \%$. По данным Управления ГИБДД ГУВД по Саратовской области, на территории города в 2008 г. зарегистрировано 249 тыс. единиц автотранспорта, из них 85\% - легковые автомобили, $15 \%$ - грузовые автомобили и автобусы [4].

В 2008 г. уровень загрязнения атмосферного воздуха характеризовался как очень высокий: расчетная величина индекса загрязнения атмосферы (ИЗА) составила 16,97 (в 2007 г. - 21,2, в 2006 г. - 22,65, в 2005 г. - 28,73). Основными загрязняющими веществами являются взвешенные вещества, оксид углерода, диоксид азота, фенол и формальдегид [4]. Даже при ежегодном снижении расчетной величины индекса загрязнения атмосферы за счет спада промышленного производства состояние воздушного бассейна Саратова оценивается областным комитетом охраны окружающей среды и природопользования как критическое и требует принятия неотложных мер.

Загрязнение атмосферы находится в тесной взаимосвязи с метеорологическими условиями. В отдельные периоды, когда неблагоприятные метеорологические условия способствуют накоплению загрязняющих веществ в приземном слое атмосферы, концентрации примесей в воздухе могут резко возрастать. М.Е. Берлянд [6] к таким параметрам относит приземные инверсии, штили, слабый ветер неблагоприятных направлений в сочетании с приземной инверсией. Э.Ю. Безуглая и Л.Р. Сонькин [7] также отмечают застой воздуха и 
устойчивый ветер с направлениями от источников загрязнения как наиболее опасные метеорологические ситуации, приводящие к повышенному загрязнению воздуха.

Обе эти ситуации весьма характерны для Саратова. В течение 2008 г. в городе были зафиксированы 83 дня с неблагоприятными метеоусловиями. Ситуация усугубляется расположением центральной части города в Приволжской котловине, где наряду с историческим центром располагаются старейшие промпредприятия. Южная часть города представлена крупными промышленными гигантами - ОАО «Саратовский нефтеперерабатывающий завод», ООО «Саратоворгсинтез». В северо-западной части Саратова сосредоточены крупные предприятия металлообработки и машиностроения. Общая циркуляция атмосферы обусловливает преобладание в Саратове северо-западного, западного и южного ветра. Средняя годовая скорость ветра в городе равна 2,8 м/с. Таким образом, на территории Саратова складывается крайне неблагоприятная обстановка, преобладающие направления ветра приносят воздух из самых техногенонагруженных участков города в его центральную селитебную часть.

Выбор локальных полигонов для проведения снеговой геохимической съемки обусловлен рядом факторов: геоморфологической позицией участка, метеорологическими особенностями, техногенной нагрузкой на данной территории. Кроме этого на выбор конфигурации и размеров полигонов повлиял анализ результатов снеговых геохимических съемок 1992-1999 годов. В 2005 г. для проведения съемки были оконтурены шесть участков городской территории, расположенные в Кировском, Фрунзенском, Октябрьском и Заводском районах Саратова. В последующие годы снеговая съемка проводилась лишь на одном полигоне, расположенном в центральной части города (рис. 1). Контуры участка: ул. Кутякова, ул. Степана Разина и ул. Новоузенская. С северо-западной стороны граница условно проведена по склону Лысогорского плато. На данной территории расположены как мало- и многоэтажные жилые здания, так и промышленные предприятия (ОАО «Электроисточник»). Район исследования пересечен густой сетью автотрасс, железнодорожной магистралью и подъездными путями станции Саратов-1.

В данной статье приводятся результаты снеговых геохимических съемок, проведенных на данном полигоне в разные годы.

\section{Методика исследований}

Изучение снегового покрова на исследуемом полигоне проводилось с целью выявления поля воздействия совокупного влияния промышленных



Рис. 1. Территория полигона с рекомендуемыми точками отбора проб снегового покрова 
выбросов города и подтверждения ранее установленных аномалий. Проведение геохимической съемки в течение нескольких зимних сезонов позволяет проследить динамику содержания отдельных компонентов в снеговом покрове.

Важным методическим вопросом является размещение пунктов опробования. Отбор проб проводился на участках, которые визуально не подвергались антропогенному воздействию и удалены от автодорог: в пределах палисадников, аллей, во дворах частных и многоэтажных домов. Для отбора проб применялся весовой снегомер ВC-43, который вертикально вжимался в толщу снежного покрова до поверхности почвы. Нижняя часть снеговой колонки $(0,5-1$ см), загрязненная почвенными частицами, отсекалась, вся остальная колонка снега вытаскивалась из трубки; отбиралась средняя проба методом конверта на площади приблизительно $10 \mathrm{~m}^{2}$ и состояла из 20-25 колонок снега [8]. Определялась мощность снегового покрова, подсчитывались его плотность и влагозапас. На каждой точке отбора проводилось краткое описание ландшафтных и геоэкологических условий. В 2005-2006 гг. на территории полигона были отобраны 16 проб, в 2007-2008 - 20 проб, а в 2008-2009 - 16 проб. Для определения фоновых значений по различным показателям проводился отбор проб за пределами города, в районе с. Усть-Курдюм (Саратовский район).

Растапливались пробы снега в течение суток в замкнутом помещении при температуре $22-25^{\circ} \mathrm{C}$. Затем талая вода очищалась через фильтр с синей лентой и разливалась по полиэтиленовым бутылкам с прикрепленными к ним сопроводительными этикетками. Объем каждой пробы составил 1,5-2,5 литра.

Сразу же после таяния и фильтрования определялся макрокомпонентный состав воды в соответствии с руководством «Унифицированные методы анализа воды» в лаборатории геоэкологии и экологической геохимии геологического факультета и на кафедре аналитической химии химического факультета СГУ. В разные годы определялись следующие ингредиенты: $\mathrm{pH} \mathrm{NH}_{4}^{+}$, $\mathrm{NO}_{2},-\mathrm{NO}_{3}^{-}, \mathrm{Cl}^{-}, \mathrm{SO}_{4}, \mathrm{HCO}_{3}^{-}, \mathrm{Ca}^{2+}, \mathrm{Mg}^{2+}$,

\section{Результаты химических исследований}

Водородный показатель (рН). Водородный показатель талой воды снегового покрова измерялся при проведении всех снегомерных съемок. На территории полигона в отобранных пробах $\mathrm{pH}$ варьирует от 6,6 до 7,7 (2005-2006 гг.), от 5,1 до 7 (2007-2008 гг.) и от 6,3 до 8,1 (2008-2009 гг.). Для фоновых проб характерен рН =6,1 (2005-2006 гг.), 6,3 (2007-2008 гг.) и 6,2 (2008-2009 гг.). При обследовании 1997 г. фоновое значение $\mathrm{pH}$ было на уровне 5,8. Сравнение результатов $\mathrm{pH}$ фоновых и городских проб свидетельствует о более щелочном характере снегового покрова на исследуемой территории. Из анализа графиков распределения pH разных лет можно сделать вывод о некотором увеличении значений водородного показателя в зимний период 2008-2009 гг. (рис. 2).

Согласно СанПиН 2.1.4.1074-01 предельно допустимые значения водородного показателя могут изменяться от 6 до 9 единиц, что, в общем, указывает на соответствие талых вод нормативным требованиям.

Азот аммония $\left(\mathrm{NH}_{4}^{+}\right)$. Ионы аммония определялись только в зимний период 2007-2008 гг. и были обнаружены во всех анализируемых пробах. Концентрация азота аммония колеблется от 0,01 до 3,61 мг/л и в среднем для исследуемого участка составляет $1,1 \mathrm{мг/л} \mathrm{(рис.} 3$ ).

Согласно СанПиН 2.1.4.1074-01 предельно допустимая концентрация содержания азота

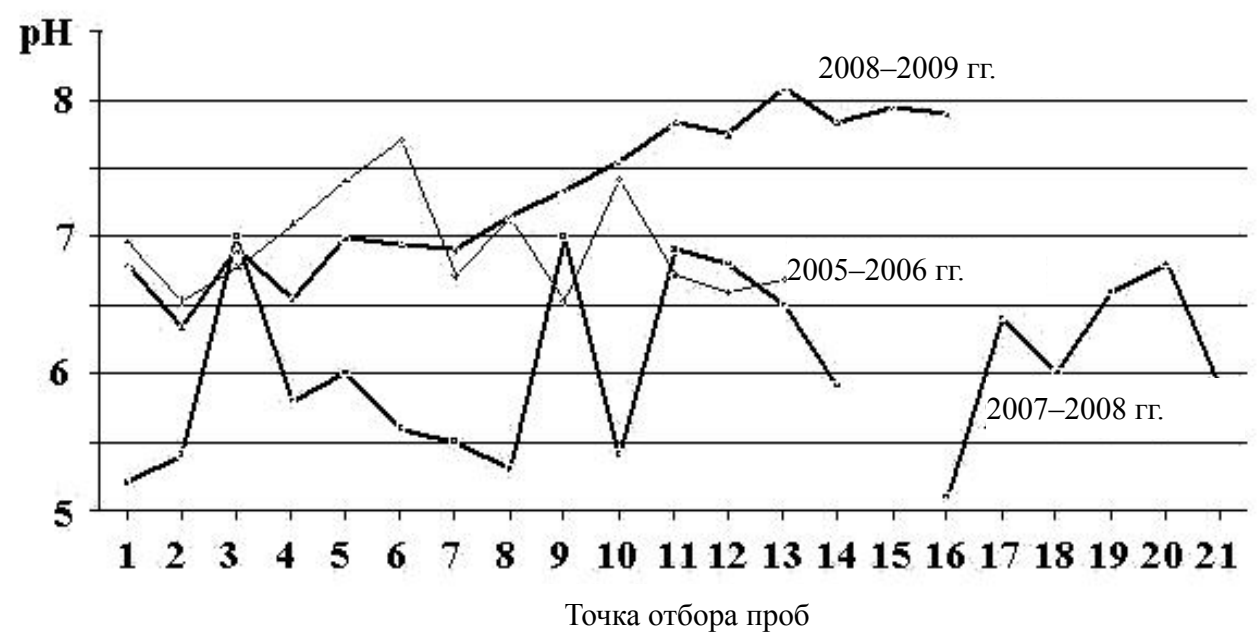

Рис. 2. График значений рН талой воды в точках отбора снеговых проб в разные годы исследований 


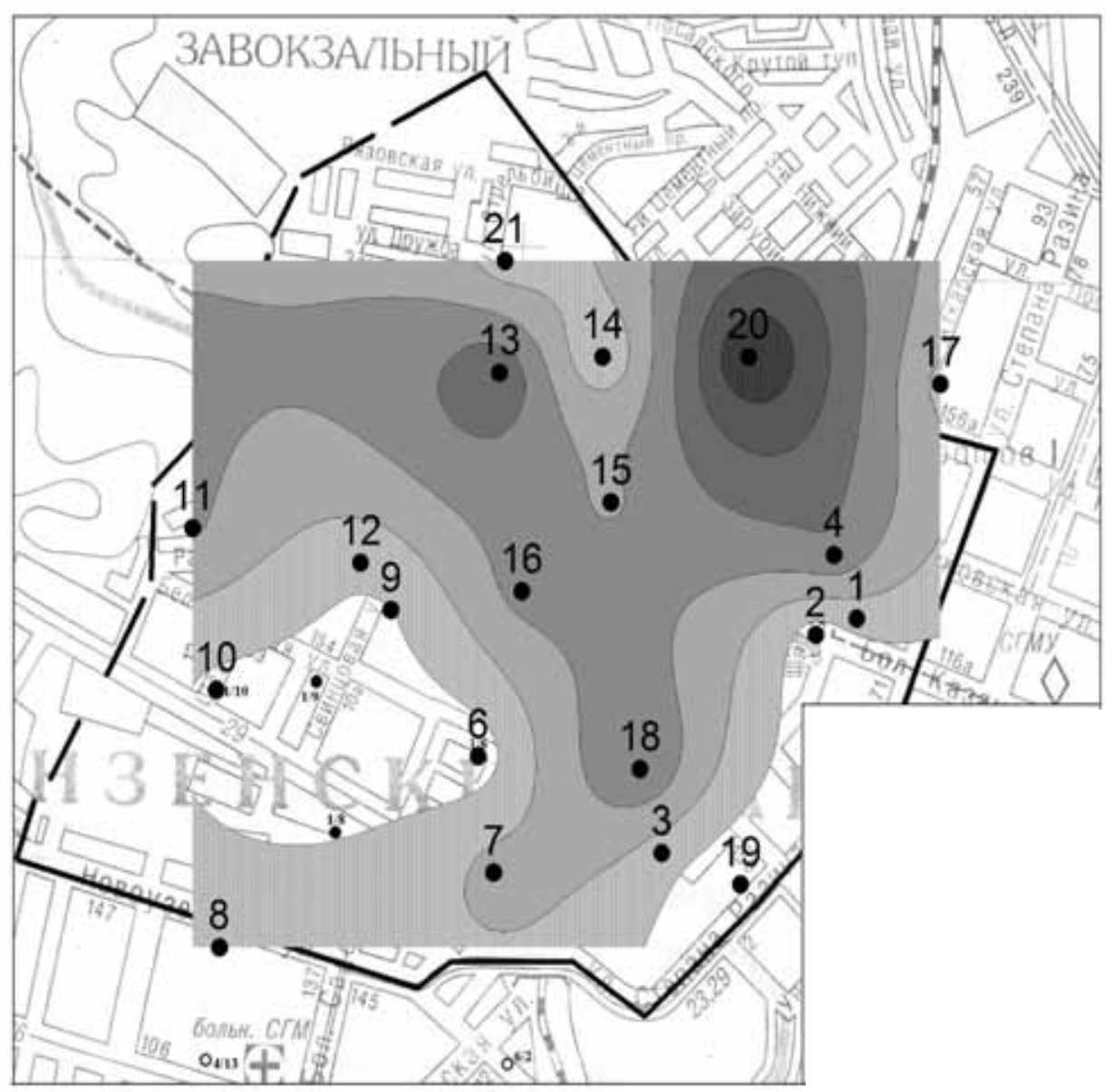

Значение концентраций, мг/л

Рис. 3. Карта-схема распределения ионов аммония в снеговом покрове исследуемого участка

аммония в водах рыбных хозяйств составляет 0,5 мг/л. Только в 6 из 20 проб значение ПДК не превышено (точки отбора 2, 6, 9, 14 и 19). Во всех остальных пробах зарегистрировано превышение ПДК от 1,2 до 7,2 раз. Наибольшая концентрация азота аммония зафиксирована во дворе жилого дома, расположенного на перекрестке ул. Кутякова и Б. Садовая. Большинство проб с повышенным содержанием азота аммония пространственно приурочены к железнодорожным путям ст. Саратов-I.

Важно отметить, что токсичность азота аммония возрастает с повышением $\mathrm{pH}$ среды, а по данным определения $\mathrm{pH}$ на исследуемой территории идет именно увеличение кислотно-щелочного потенциала.

Нитриты $\left(\mathrm{NO}_{2}^{-}\right)$. Нитриты определялись в 2 зимних сезонах и были обнаружены практически во всех исследуемых пробах в концентрации от 0,06 до 0,44 мг/л (2005-2006 гг.) и от 0,1 до 0,7 мг/л (2007-2008 гг.). Наблюдается рост содержания нитритов во всех исследуемых точках отбора. Наибольшие концентрации нитритов (по последним данным) зарегистрированы в точках отбора 9 и 12 (рис. 4). Превышение над фоновыми значениями (0,03 мг/л) составляет от 2 до
23 раз, но ни в одной пробе не зафиксированы значения, превышающие ПДК (согласно СанПиН 2.1.4.1074-01, предельно допустимая концентрация содержания нитритов в водах рыбных хозяйств составляет 3,0 мг/л).

Хлориды $\left(\mathrm{Cl}^{-}\right)$. Концентрация хлоридов в исследуемых пробах изменяется в широком диапазоне - от 3,5 до 177 мг/л (2007-2008 гг.) и от 10,7 до 213 мг/л (2008-2009 гг.). Фоновое значение составляет приблизительно 8,1 мг/л, соответственно максимально оно превышается в 22 (в 2007-2008 гг.) и 26 раз (в 2008-2009 гг.). Анализ результатов позволяет сделать вывод о возрастании концентрации хлоридов в пробах 2008-2009 гг. по сравнению с предыдущим годом отбора снеговых проб в 1,5-6 раз, которая достигает 30-кратного превышения в точке отбора 1 (между корпусами 6 и 7 СГУ) и 46-кратного - в точке отбора 4 на Привокзальной площади.

Предельно допустимая концентрация содержания хлоридов в водах рыбных хозяйств составляет 300 мг/л. На исследуемом участке в пробах талой воды концентрация хлоридов не превышает установленных нормативных показателей, следовательно, по данному показателю она относится к типу чистых. 
Сульфаты $\left(\mathrm{SO}_{4}^{-}\right)$. Сульфаты задокументированы в 18 из 20 проб, отобранных в зимний период 2007-2008 годах. Их концентрация колеблется в пределах от 2,3 до $22,7 \mathrm{мг} /$, при средних значениях 5,8 мг/л. В сезон 2008-2009 гг. сульфаты были обнаружены во всех 16 отобранных пробах, их концентрация изменялась от 8,0 до 60,0 мг/л, при средних значениях 29,6 мг/л. Несомненно, отмечается существенный рост концентрации сульфатов во всех точках отбора снеговых проб 2008-2009 гг. по сравнению с 2007-2008 годами. (рис. 5). Наибольшие концентрации зафиксированы в пробах 12 и 16 в 2007-2008 гг. и в пробах 1, 5, 10 и 13 в 2008-2009 годах.

Фоновое содержание сульфатов составляет 5,14 мг/л, соответственно максимально оно превышается по сезонам в 4,4 раза (2007-2008 гг.) и 11,6 (2008-2009 гг.). Согласно СанПиН 2.1.4.1074-01 предельно допустимая концентрация содержания сульфатов в водах рыбных хозяйств составляет 100 мг/л. Концентрация сульфатов на исследо- ванном полигоне не превышает установленных нормативных показателей.

Сухой остаток. Содержание сухого остатка в талых водах (2007-2008 гг.) варьирует от 20 до 180 мг/л. Наибольшее содержание сухого остатка зафиксировано в точках отбора 10 и 18. В подавляющем количестве проб эти значения находятся в пределах 30-60 мг/л. Сопоставляя полученные данные с результатами исследований 90-х гг., можно сделать вывод, что произошло повышение содержания сухого остатка в снеговом покрове. Например, при снегомерной съемке 1997 г. для большей части Саратова были характерны значения в пределах от 20 до 60 мг/л.

Согласно СанПиН 2.1.4.1074-01 предельно допустимая концентрация сухого остатка в водах рыбных хозяйств составляет 1000 мг/л. Таким образом, на исследуемом участке в пробах талой воды содержание сухого остатка не превышает установленных нормативных показателей, следовательно, по данному показателю она относится к типу чистых.

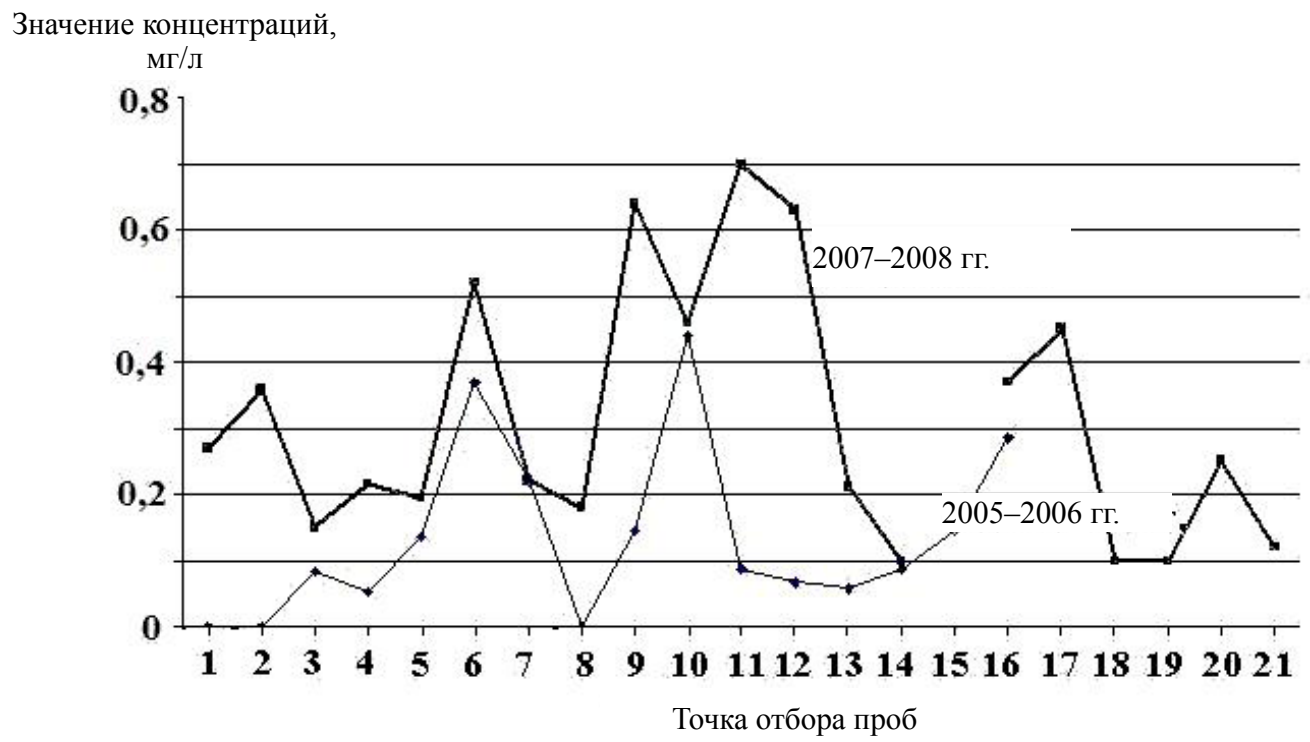

Рис. 4. График значений содержания нитритов (мг/л) в снеговых пробах в разные годы исследований

Значение концентраций,

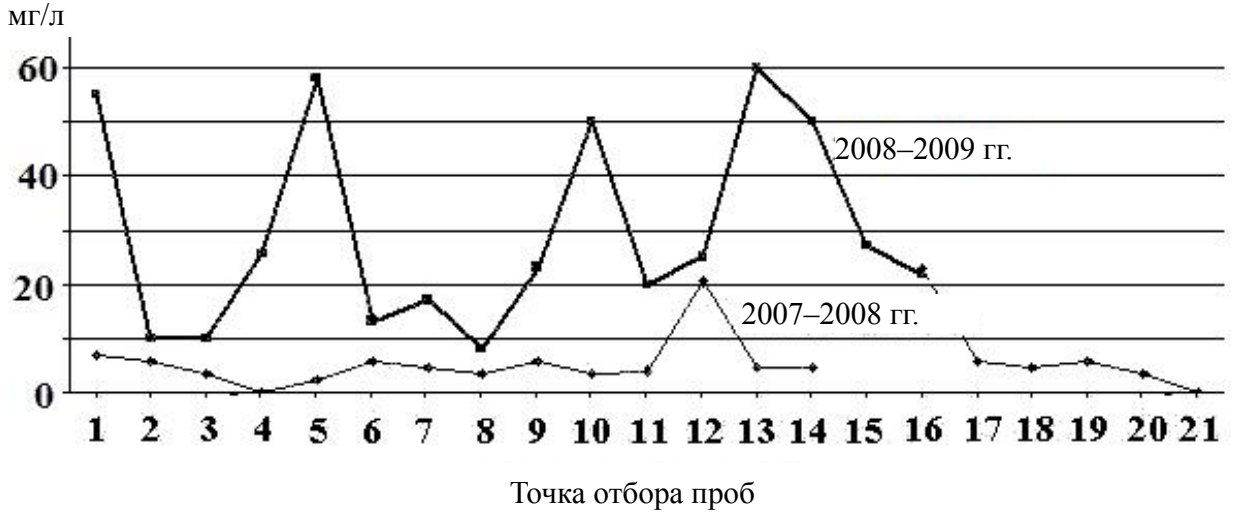

Рис. 5. График значений содержания сульфатов (мг/л) в снеговых пробах в разные годы исследований 


\section{Общие выводы}

Снегометрические съемки, проводимые по программе ЭМ ${ }^{\circ} \mathrm{C}$ в 90-х гг. ХХ в., дали представление об основных загрязнителях, а также о конфигурации и структуре снегового геохимического поля Саратова. В настоящее время снеговая съемка с отбором нескольких сотен проб уступает место мониторинговым исследованиям на локальных, наиболее проблематичных в геохимическом отношении участках города. Начиная с 2005 года небольшими инициативными студенческими группами под руководством сотрудников лаборатории геоэкологии и экологической геохимии СГУ проводятся исследования на небольших по площади полигонах. Проведенные студентами снегомерные съемки 2005-2009 гг. позволили получить новую геохимическую информацию, сравнить новые данные с результатами предыдущих съемок. Анализ полученных данных позволяет сделать вывод, что на исследуемой территории зафиксировано превышение предельно допустимых концентраций азота аммония до 7 раз. По остальным проанализированным компонентам превышение нормативных показателей не задокументировано, но практически по всем компонентам фиксируются повышенные концентрации по сравнению с фоновыми значениями.

Важно отметить, что целью проведения снеговых геохимических съемок на локальных полигонах является не только получение новой информации, но и приобретение студентами навыков в эколого-геохимических исследованиях.

\section{Библиографический список}

1. Павленко И.А., Батоян В.В., Кучумова Н.А. Выявление зон промышленного загрязнения по исследованию снежного покрова // Техногенные потоки вещества в ландшафтах и состояние экосистем / Под ред. М.А. Глазовской. М., 1981.

2. Осокин И.М. Химический состав снежного покрова на территории СССР // Изв. АН СССР. Сер. Геогр. 1963. № 3. С. 26-34.

3. Вашков В.И., Постников П.А., Самонова В.И. Определение загрязнения местности промышленными отходами по исследованию снежного покрова // Гигиена и санитария. 1936. № 9. C. 18-23.

4. Доклад о состоянии и об охране окружающей среды Саратовской области в 2008 году. Саратов, 2009. 320 с.

5. Решетников М.В. Результаты снеговой съёмки 2005г. на территории Октябрьского и Фрунзенского районов г. Саратова // Геологи XXI: Материалы VII Всерос. науч. конф. студ., асп. и молодых специалистов / Под ред. Е.Н. Волковой. Саратов, 2006. С. 138.

6. Берлянд M.E. Атмосферная диффузия и загрязнение // Всесоюз. Тр. ГГО. 1975. Вып. 325. С. 3-26.

7. Безуглая Э.Ю., Сонькин Л.Р. Влияние метеорологических условий на загрязнение воздуха городов Советского Союза // Метеорологические аспекты загрязнения атмосферы: Сб. докл. на Междунар. симпозиуме. Л., 1971. C. 241-251.

8. Глазовский Н.Ф., Злобина А.И., Учватов В.П. Химический состав снежного покрова некоторых районов Верхнеокского бассейна. Пущино, 1978. С. 28. 